\title{
The Evaluation of Solid Particle Erosion in Polymethyl Methacrylate by Surface Topography Mapping
}

\author{
S. FIDAN \\ Kocaeli University, School of Civil Aviation, Arslanbey Campus, 41285 Kocaeli, Turkey
}

\begin{abstract}
The present work introduces and demonstrates a novel high resolution surface topography method for mapping the distribution of erosive wear in polymethyl methacrylate. The technique is based on grayvalues obtained from eroded sample surfaces and three-dimensional surface topography mapping from these grayvalues. Surface topography maps make it a valuable method for fundamental studies on erosive wear. In the present investigation, a flatbed scanner system has been used for obtaining the surface images of eroded test samples. Polymethyl methacrylate test samples eroded with 80 and 120 mesh alumina particles at 1.5 and 3 bar blast pressures and their surface topography maps compared. Erosive wear is difficult to visualize for its dynamic and complex nature, hence monitoring of erosive wear in industrial applications is rather important. High resolution surface topography method detail capturing capability may improve tribological surface damage characterization of real machine elements. Reduced costs and simplicity two primary outcomes of using a simple flatbed scanner system in non destructive testing of erosive wear.
\end{abstract}

DOI: $10.12693 /$ APhysPolA.125.494

PACS: 78.68.+m, 42.79.Ls, 42.87.-d, 81.05.Qk

\section{Introduction}

Polymethyl methacrylate (PMMA) is a transparent thermoplastic, often used as a lightweight or shatter-resistant alternative to glass. High transparency characteristic of PMMA makes it a valuable engineering material nowadays and is used in the lenses of exterior lights of automobiles, viewing ports of submersibles and in aircraft as passanger windows or windshields. Especially primary surfaces such as aircraft windshields exposed to impingement of high speed solid particles, they may lose their mechanical and optical transparency properties. The loss of transparency in an aircraft windshield has a crucial effect on outside visibility and flight safety.

Erosive wear of materials occurs by removal of target material from impact zone, due to repeated impacts of erodent, by a micromechanical deformation/fracture process [1-3]. Solid particle erosion phenomenon has a complex characteristic, therefore it is crucial to visualize the damage on target materials surface for evaluation of damage mode. Researchers have been working on developing novel methods for material wear characterization for many years. They have attempted to take advantage of image analysis methods in order to achieve their goals. Nowadays, flatbed scanners, digital cameras and optical microscopes are used as attractive devices in order to set up an image analysis system by researchers $[4,5]$. In this study, solid particle erosion behavior of PMMA has been examined in detail by using a novel surface analysis method in order to figure out the effect of abrasive particle size and blast pressure. To achieve this goal, grayvalues were obtained from high resolution scanned images of eroded PMMA samples. It is aimed to visualize the surface topography of eroded PMMA as $3 \mathrm{D}$ rendered view.

\section{Materials and methods}

PMMA sheets commercially named Altuglas CN with a nominal thickness of $10 \mathrm{~mm}$ were selected as test materials. The test specimens are prepared in $30 \mathrm{~mm} \times$ $20 \mathrm{~mm}$ by cutting out from PMMA sheets of $200 \mathrm{~mm} \times$ $200 \mathrm{~mm}$. Table I gives the mechanical and optical properties of PMMA test samples, according to the manufacturer's declaration.

TABLE I

Mechanical and optical properties of PMMA samples.

\begin{tabular}{c|c|c|c}
\hline \hline Mechanical properties & Test method & Units & Value \\
\hline density & DIN53479 & & 1.19 \\
Poisson ratio to $20{ }^{\circ} \mathrm{C}$ & & & 0.39 \\
hardness, shore scale M & ASTM D 785 & & 100 \\
\hline Optical properties & Test method & Units & Value \\
\hline light transmittance & DIN5036 & $\%$ & 92 \\
refractive index & DIN53491 & & 1.492
\end{tabular}

The erosion test rig used in this study is illustrated in Fig. 1. Accelerated particles impacted the specimen, which can be hold at various impingement angles $\left(15^{\circ}-90^{\circ}\right)$ by adjustable sample holder shown in Fig. 1. Solid particle erosion test parameters are given in Table II.

To capture the image of PMMA test specimens, HP Scanjet G2710 flatbed scanner is used. The scanner comprises an opaque cover to hold the subject on top of the glass pane, an illumination source, CCD sensors and software solutions for image processing. The sample to be scanned is placed face down on the glass, the opaque cover is lowered over it to exclude ambient light. The sensor array and light source move across the pane by carriage, reading the entire area. Scanning parameters of PMMA samples and HP Scanjet G2710 flatbed photo 


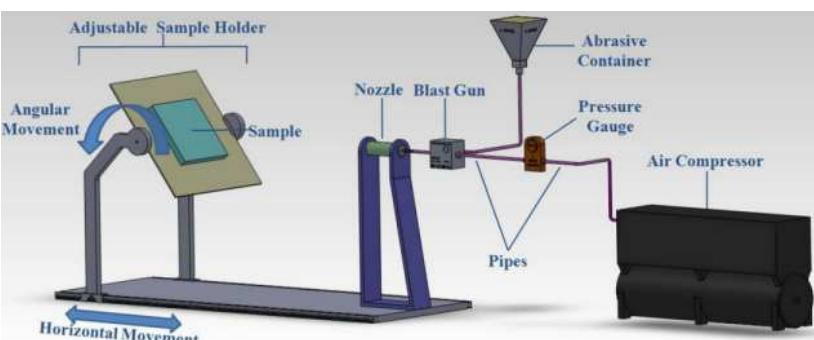

Fig. 1. Solid particle erosion test rig.

Solid particle erosion test parameters.

TABLE II

\begin{tabular}{c|c}
\hline \hline erodent type & alumina $\left(\mathrm{Al}_{2} \mathrm{O}_{3}\right)$ \\
erodent size & 80 mesh $(150-212 \mu \mathrm{m})$, \\
120 mesh $(90-125 \mu \mathrm{m})$ \\
particle impingement angle & $45^{\circ}$ \\
acceleration/blast gun pressure & $1.5 \mathrm{bar}, 3 \mathrm{bar}$ \\
test temperature & $25^{\circ} \mathrm{C}$ \\
nozzle diameter & $5 \mathrm{~mm}$ \\
nozzle length & $50 \mathrm{~mm}$
\end{tabular}

scanner technical specifications are given in Table III. An open-coded image processing program named Image J was used to obtain grayvalues of eroded PMMA samples and 3D topography mapping of surface erosion crater.

\section{Results and discussion}

In Fig. 2, the erosion rates of the PMMA specimens eroded with 80 and 120 mesh abrasive particles at 1.5 bar (Fig. 2a) and at 3 bar (Fig. 2b) are given and compared. At 1.5 bar blast pressure, 80 mesh particles caused a higher erosion rate than 120 mesh particles so decreasing particle size at 1.5 bar also decreases the erosion rate. This is also reported in literature by other researchers $[6,7]$. The tests were carried out at $45^{\circ}$ impingement angle in order to simulate maximum erosion rate. Decreasing the particle size at 3 bar increases the erosion rate of PMMA. It can be concluded that increasing blast pressure from 1.5 bar to 3 bar changes the material removal mechanism of the eroded PMMA and increases the erosion rate. As a result, it can be said that both particle size of erodent particle and blast pressure greatly affects the erosion rate of PMMA.

TABLE III

Scanning parameters and HP Scanjet G2710 specifications.

\begin{tabular}{c|c}
\hline \hline \multicolumn{2}{c}{ Scanning parameters } \\
\hline $\begin{array}{c}\text { Image pixel size } \\
(\text { width } \times \text { height })\end{array}$ & $1890 \times 2835 \mathrm{dpi}$ \\
bit depth & $(20 \mathrm{~mm} \times 30 \mathrm{~mm})$ \\
\hline HP Scanjet G2710 & flatbed scanner specifications \\
\hline levels of grayscale & 256 \\
scanning wavelengths & $395,450,520,590,650,850 \mathrm{~nm}$
\end{tabular}

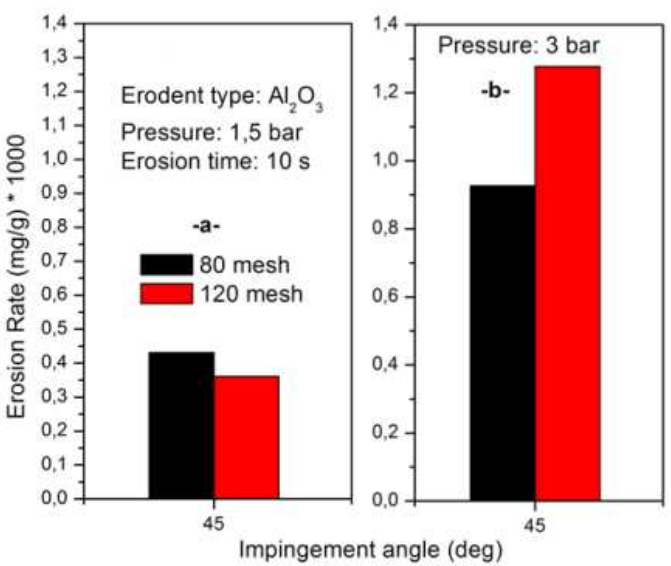

Fig. 2. The variation of erosion rates of PMMA eroded with 80 mesh and 120 mesh alumina particles at different blast pressures (a) 1.5 bar, (b) 3 bar.

The surface damage visualization of eroded PMMA samples was constituted by using a novel imaging method. Surfaces of eroded PMMA samples were scanned with a flatbed scanner system. High resolution $2 \mathrm{D}$ images of eroded surfaces taken from scanning process were edited by an image processing program named Image J. Image J was used in transforming $2 \mathrm{D}$ images to grayvalue histograms. If a transparent material like PMMA deteriorates by an external solid particle hitting on its surface at high speeds, a crucial transparency loss occurs. Transparency loss of material is a perceivable damage, if appropriate image processing algorithm is used. The grayvalue histogram algorithm was used in this paper in order to visualize the transparency loss due to solid particle erosion in PMMA. In Fig. 3, the grayvalue histograms of eroded PMMA samples were given. In Fig. 3a and b it is concluded that grayvalue 100 implies the transition region from transparent to non-transparent after solid particle erosion damage.

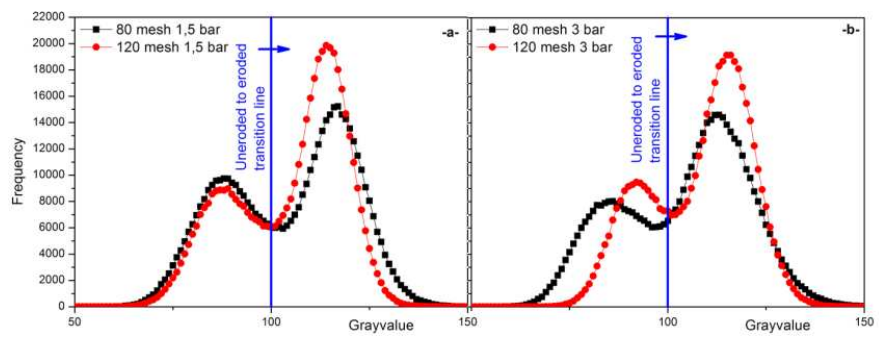

Fig. 3. Grayvalue histograms of eroded PMMA samples at (a) 1.5 bar, (b) 3 bar blast pressures.

In Fig. 4 scanned surface 2D images and 3D surface topography maps obtained from grayvalues of scanned surfaces were given. For both erodent particle size, increasing blast pressure enhances erosion surface crater depth. Moreover, increasing the blast pressure also causes the roughness to increase and homogenize at the bottom of 


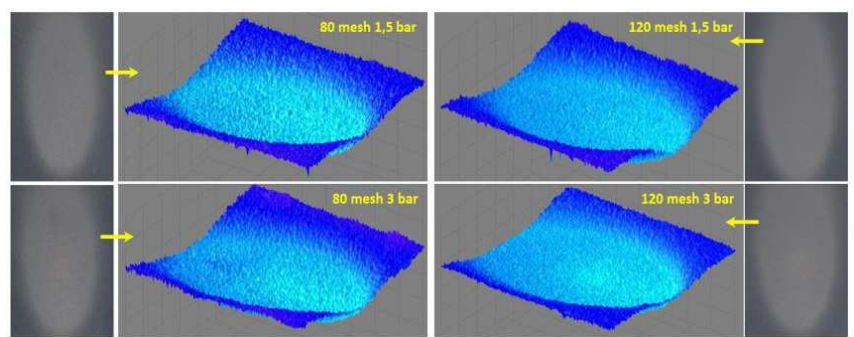

Fig. 4. Surface images and 3D topography maps of the eroded PMMA samples.

the erosion damage crater. By the help of proposed surface damage visualization method, it is possible to observe the roughness of eroded samples surfaces. Roughness is directly proportional to the light reflection characteristic of a surface. The surface topography mapping process also figure out the effect of particle size on solid particle erosion surface damage. Increasing erodent particle size boost the surface roughness of the eroded samples due to sharp angularity of erodent.
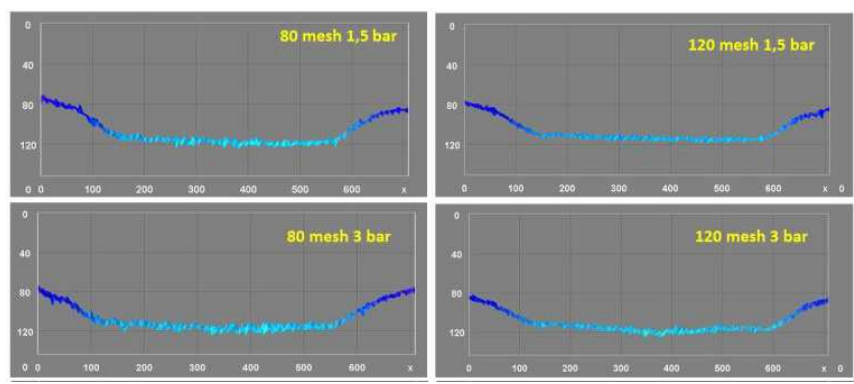

Fig. 5. Surface crater depth 3D maps of eroded PMMA samples.

Through the thickness surface crater 3D maps of eroded PMMA samples were given in Fig. 5. To identify the surface erosion damage crater dimensions, maximum depth and cross-sectional areas of the eroded surfaces were visualized by grayvalue 3D mapping process. Coarse particles like 80 mesh figure out a rougher surface topography when compared with 120 mesh erodent. Blast pressure effect can be negligible in 80 mesh erodent size while it increases the depth of erosion crater in 120 mesh.

\section{Conclusions}

This study experimentally investigates the erosion damage characteristics of PMMA by using a novel sur- face analysis method based on grayscale histograms. Transparent PMMA samples eroded with 80 mesh and 120 mesh alumina particles at $45^{\circ}$ impingement angles with 1.5 bar and 3 bar blast pressures, respectively. 3D surface topography maps were generated from the gray values of eroded samples. Based on these studies, the following conclusions can be drawn:

1. At 1.5 bar blast pressure, the erosion rate of PMMA was higher when eroded with 80 mesh alumina particles. On the other hand, when blast pressure increased to 3 bar, maximum erosion rate observed in PMMA samples eroded with 120 mesh alumina particles. So blast pressure dramatically changes the effect of particle size on erosive wear and damage mode of PMMA.

2. Light reflectance characteristic and grayvalue histograms of eroded PMMA give valuable information about transparency loss. Increased grayvalues due to solid particle erosion point out a haze effect on the surface of PMMA and stand alone as an evidence of polymeric degradation. Degradation of polymeric bonds leads to amorphous structure caused by solid particle erosion damage.

3. A simple flatbed scanner and appropriate image processing algorithm can be used to expose the dominant erosion mechanism of PMMA at various test conditions. Damage evaluation of polymeric materials by using proposed image processing technique promises a low cost, timesaving and eligible method for non-destructive inspection.

\section{References}

[1] E. Avcu, S. Fidan, S. Karabay, T. Sinmazçelik, J. Fac. Eng. Archit. Gaz. 27, 865 (2012).

[2] E. Avcu, S. Fidan, M.Ö. Bora, O. Çoban, İ. Taşkiran, T. Sinmazçelik, Adv. Polym. Technol. 32, 386 (2013).

[3] T. Sınmazçelik, S. Fidan, V. Günay, Mater. Des. 29, 1419 (2008).

[4] T.Y. Lim, M.M. Ratnam, Opt. Lasers Eng. 50, 1628 (2012).

[5] K.L. Yam, S.E. Papadakis, J. Food Eng. 61, 137 (2004).

[6] D.P. Mondal, S. Das, A.K. Jha, A.H. Yegneswaran, Wear 223, 131 (1998).

[7] M. Dundar, O.T. Inal, Wear 224, 226 (1999). 